\title{
Urgences
}

\section{Nocturno pour Nezahualcoyotl}

\section{Claude Beausoleil}

Numéro 33, octobre 1991

Poésies parallèles : France - Québec

URI : https://id.erudit.org/iderudit/025672ar

DOI : https://doi.org/10.7202/025672ar

Aller au sommaire du numéro

Éditeur(s)

Urgences

ISSN

0226-9554 (imprimé)

1927-3924 (numérique)

Découvrir la revue

Citer ce document

Beausoleil, C. (1991). Nocturno pour Nezahualcoyotl. Urgences, (33).

https://doi.org/10.7202/025672ar d'utilisation que vous pouvez consulter en ligne.

https://apropos.erudit.org/fr/usagers/politique-dutilisation/ 


\title{
Nocturno pour Nezahualcoyotl
}

\section{Claude Beausoleil}

\author{
Non pas pour toujours ici sur la terre, \\ Mais seulement pour un bref instant. \\ NezahuaLCOYOTL
}

Non ce n'est pas vrai Nezahualcoyotl tu as raison

Que nous sommes venus sur terre pour vivre

Nous sommes de passage voyageurs du rêve

Dans des villes édifiées au vent du temps qui passe

Par l'idée du voyage devenu contemplation

Les figures se superposent

Les instants et la fuite tout va vers un ici

Nous y trouvons la route dans les dédales de Mexico

Aux croisements des ruptures

Et je ne sais pas nommer ta tristesse

Le long des rues défaites tu gardes ton secret

Ton odeur d'avenue aux arbres rares et gris

La rumeur de tes automobiles à l'heure des retours

Ne sait pas où se multiplie ton mystère

Mexico tu changes et tu demeures

Tu parles largement de tes mythologies

Un instant tu t'arrêtes

Transmets l'âme des foules au chant des solitudes

Des blocs turquoise découpent les cubes grisâtres

Plus loin on construit ce que le hasard a détruit

Les miroirs masquent l'ampleur des recommencements

Je ne sais pas nommer tes écroulements

Ta patience tes saveurs et tes odeurs violentes

La plus ordinaire de tes images m'échappe

Je ne sais pas je ne sais plus écrire tes connivences

Non ce n'est pas vrai les images le réel

Non je ne vois pas ce qui défile à l'horizon 
94

Seul je vais les façades m'accompagnent Je me sens envoûté perdu dans un taxi Le trafic a dépassé depuis longtemps

Les lois d'une logique quelconque

Tu sais renaître Mexico

Réinventer le regard fraternel

Emplir le jour d'éternité quand surgissent des scènes Plus réelles que la bouche du temps

Un destin de ville que tu esquisses Mexico

Reprend les angles retouchés

Abandonne les lignes et l'ordre

J'aime t'espérer j'aime tes rues

Ton visage de nécessité tes maquillages suggestifs

Tes inventions vitales

Je décris une idée celle d'un voyage dans le réel Je suis venu rêver que toutes les nuits s'assemblent

Non ce n'est pas vrai que la vie nous déplace C'est le temps qui nous crée 


\section{Nocturno de Mexico}

à la manière des Contemporaneos

las cinco letras del DESEO formarian una enorme cicatriz luminosa.

XAVIER VILLAURRUTIA, Nocturno de Los Angeles

Ton poème s'échappe des mots de Villaurrutia

Enrobant la ville d'ombres de statues muettes

D’anges désolés

D'images noires et crayeuses insinuées

Au bout d'un espoir où tout peut chavirer

Les odeurs de la rue emportent le mystère

Plus loin encore de l'autre

Cet autre presque inventé

Sur le fil extérieur où le doute submerge la réalité

Autant fuir par les rues

Tout s'y prête sans renoncement

Sans déplacer le ciel trop mauve à cette heure

Dans ses torsions d'orange au tumulte opaque

Autant donner son désir au vent humide

Que le soir a charrié vers les parcs insomniaques

Au détour d'un rêve

Dans la pierre des immeubles

Où dorment des sourires

D'avant la fin du silence

Tu rôdes autour de l'ange de l'indépendance

Oscillant sous les lumières des phares 
96

Structure diffractée plus secrète qu'un corps

Caché dans l'entrée d'un hôtel

Trop fastueux pour contenir son rêve

La chance t'accompagne vers ici vers lui

Un instant des présences dessinent des amours

La voix nocturne d'une radio

Un parc neuf entouré de voitures livides

Des oiseaux à un ange ont donné leur couleur

L'air se fait plus torsadé quand la nuit apparaît

Dans le chant brûlant d'une cantina

Les sources d'une passion indistincte

Transpercent les échos et bousculent la mort

Des ondes suaves de griseries finales

Marquent ton arrivée dans l'oralité des choses

Tu prends des routes aux méandres fiévreux

Tu parles comme un ange

Est-ce toi qui l'écrit ce dialogue nocturne

Rappelant tant de nuits

D'espoirs irrésolus

Que nos trop pauvres esprits rejettent dans le vide

Tu ne dormiras pas

Les caresses sont si tendres dans la main du destin

Ta sueur rutile encre ambrée lueur d'âme

Un seuil s'ouvre sous les couches de lune

Tout cela tu l'entoures d'une précision noire

Ciudad Ciudad quand la nuit ferme tes yeux

Tu te souviens d'un poème dans un livre acheté

Près d'un temple où la nuit rôdent d'autres amants

Un Nocturno comme aiment en écrire les poètes mexicains

Ce poème te parle d'un mal aux ravages sombres

Il nomme l'absolu le seul lieu du bonheur

Il est écrit dans la tristesse et l'immensité

Du mot DÉSIR

D'autres poètes d'autres nuits

Y sont venus rêver 
Lis-le bel ange

Les lumières de la rue dirigeront tes pas

Lis-le

Il va en toi découvrir le néant

L'amour possible

Les autres temps

L'immatériel

Un rêve sans fin

Une destinée perdue et retrouvée

Dans la ville et ses lieux où naissent les Nocturnes

Tu y détourneras tes angoisses pour un moment

Un seul moment et la ville vacille

Ce poème te parle du cœur de l'amour

De la chute et des chants

De la hantise des ans

Du périple dans la ville sous les deuils lumineux

Ton corps glisse soudain en des lieux inconnus

L'ange a quitté les zones incertaines

Il titube ou s'ajuste

La vie est à ce prix

Tu l'écoutes gémir

La nuit est une amie

Une mère insondable aux rumeurs d'origine

L'air est plus poétique

Le matin se fait attendre sur la liberté des yeux

Le fleuve est une larme amère sur ta joue blanche

Tu retraverses le temps sous les lignes brisées

Qu'un dernier regard n'a pas cru retenir

L'amour n'est pas le temps

C'est toi que tu poursuis au hasard de ces rues

Et au bord de l'abîme tu livres tes combats 